\title{
Mule determines the apoptotic response to HDAC inhibitors by targeted ubiquitination and destruction of HDAC2
}

\author{
Jing Zhang, ${ }^{1}$ Shu Kan, ${ }^{1}$ Brian Huang, ${ }^{1}$ Zhenyue Hao, ${ }^{2}$ Tak W. Mak, ${ }^{2}$ and Qing Zhong ${ }^{1,3}$ \\ ${ }^{1}$ Division of Biochemistry and Molecular Biology, Department of Molecular and Cell Biology, University of California \\ at Berkeley, Berkeley, California 94720, USA; ${ }^{2}$ Campbell Family Institute for Cancer Research and Ontario Cancer Institute, \\ University Health Network, Toronto, Ontario M5G 2M9, Canada
}

\begin{abstract}
Histone deacetylases (HDACs) are major epigenetic modulators involved in a broad spectrum of human diseases including cancers. Administration of HDAC inhibitors (HDACis) leads to growth inhibition, differentiation, and apoptosis of cancer cells. Understanding the regulatory mechanism of HDACs is imperative to harness the therapeutic potentials of HDACis. Here we show that HDACi- and DNA damage-induced apoptosis are severely compromised in mouse embryonic fibroblasts lacking a HECT domain ubiquitin ligase, Mule (Mcl-1 ubiquitin ligase E3). Mule specifically targets HDAC2 for ubiquitination and degradation. Accumulation of HDAC2 in Mule-deficient cells leads to compromised p53 acetylation as well as crippled p53 transcriptional activation, accumulation, and apoptotic response upon DNA damage and Nutlin-3 treatments. These defects in Mule-null cells can be partially reversed by HDACis and fully rescued by lowering the elevated HDAC2 in Mule-null cells to the normal levels as in wild-type cells. Taken together, our results reveal a critical regulatory mechanism of HDAC2 by Mule and suggest this pathway determines the cellular response to HDACis and DNA damage.
\end{abstract}

[Keywords: apoptosis; Mule; HDAC2; ubiquitination; DNA damage; p53]

Supplemental material is available for this article.

Received May 23, 2011; revised version accepted September 19, 2011.

Acetylation, a key epigenetic modulator of chromatin structure and gene transcription, is tightly controlled by competing actions of histone acetyltransferase (HAT) and histone deacetylase (HDAC) activities (de Ruijter et al. 2003; Blander and Guarente 2004). Hyperacetylation of the $\mathrm{N}$ terminus of histone tails induced by HATs correlates with gene activation, whereas deacetylation by HDACs has been shown to mediate transcriptional suppression (Strahl and Allis 2000). Consequently, HDACs play critical roles in cellular growth, differentiation, apoptosis, and transformation; dysregulation of acetylation status in the cell is closely linked to cancer (Haberland et al. 2009).

HDACs have been classified into different subfamilies based on phylogenetic analysis and sequence homology in mammals (de Ruijter et al. 2003). The class I HDACs, which include HDAC1-3 and HDAC8, are homologous to yeast RPD3. They are ubiquitously expressed enzymes that show the strongest HDAC activity, which deacetylate both histone and nonhistone proteins in vitro and in vivo. The class II HDACs consist of HDAC4, HDAC5,

\footnotetext{
${ }^{3}$ Corresponding author.

E-mail qingzhong@berkeley.edu.

Article published online ahead of print. Article and publication date are online at http://www.genesdev.org/cgi/doi/10.1101/gad.170605.111.
}

HDAC6, HDAC7, and HDAC9 and are more similar to yeast Hda1. These HDACs are weaker enzymes and more tissue-specific compared with the class I HDACs. Class III HDACs, also known as sirtuins, are mammalian homologs to yeast Sir2 and biochemically act as NAD-dependent enzymes. Although HDACs within the same class share similar functions, individual HDACs might have a unique physiological function in pathogenesis. For example, HDAC2 has a more important role on proper synaptogenesis and memory formation than HDAC1 (Guan et al. 2009), and the gradual reduction of HDAC2 in lung alveolar cells correlates with the severity of chronic obstructive pulmonary disease (COPD) (Barnes 2005, 2009).

In addition to histones, several nonhistone targets of HDACs have been identified (Glozak et al. 2005). The best example is the tumor suppressor p53 (Luo et al. 2000; Vaziri et al. 2001). p53 plays a central role in the DNA damage response (Levine 1997). Upon stress, p53 is acetylated and phosphorylated, followed by its accumulation and its transcriptional activation of $\mathrm{p} 21, \mathrm{Mdm} 2, \mathrm{Bax}$, Puma, and Noxa due to its dissociation from its ubiquitin ligase, Mdm2 (Shieh et al. 1997; Li et al. 2002; Feng et al. 2005; Menendez et al. 2009; Beckerman and Prives 2010), which subsequently leads to cell cycle arrest and apoptosis (Lakin and Jackson 1999). The acetylation of p53 is 
regulated by HATs and HDACs (Gu and Roeder 1997; Luo et al. 2000; Vogelstein et al. 2000; Vaziri et al. 2001). Both HDAC1 (class I) and SIRT1 (class III) were reported to deacetylate p53, resulting in transcriptional inhibition. More recently, $\mathrm{HDAC} 1$ and $\mathrm{HDAC} 2$ were shown to suppress p53 hyperacetylation in embryonic epidermis (LeBoeuf et al. 2010). However, it is not clear whether HDAC2 has a direct impact on p53 function.

Recently, HDAC inhibitors (HDACis) were found to have anti-cancer functions as a novel therapeutic class of drugs in cancer therapy. So far, at least 80 clinical trials are under way to test $>11$ different HDAC inhibitory agents targeted toward class I and II HDACs against both hematological and solid malignancies (Tan et al. 2010). The clinical activity of HDACis is thought to be due to the more open chromatin structure and potential reactivation of aberrantly suppressed genes, leading to growth arrest, cell differentiation, and apoptosis of tumor cells (Vigushin and Coombes 2002; Balakin et al. 2007; Mottet and Castronovo 2008; Shankar and Srivastava 2008; Witt et al. 2009; Tan et al. 2010). These inhibitors also influence the DNA damage response through acetylation of key DNA repair and checkpoint proteins (Choudhary et al. 2009; Robert et al. 2011). Still, our knowledge about these inhibitors remains limited; understanding the regulatory mechanism of HDACs is imperative to reveal the therapeutic potential of HDACis.

Mule (Mcl-1 ubiquitin ligase E3) is a recently identified HECT domain-containing ubiquitin ligase (E3) that plays a critical role in the DNA damage response. Mule was first identified as a ubiquitin ligase for an anti-apoptotic Bcl-2 family protein, Mcl-1 (Zhong et al. 2005). Mule is also known as ARF-BP1, Ureb1, LASU1, HUWE1, or HectH9, and promotes ubiquitin-proteasomal degradation of multiple substrates, including p53, c-Myc, Cdc6, histones, N-Myc, Miz1, TopBP1, and Pol $\beta$ (Adhikary et al. 2005; Chen et al. 2005; Zhong et al. 2005; Hall et al. 2007; Liu et al. 2007; Herold et al. 2008; Zhao et al. 2008; Parsons et al. 2009; Yang et al. 2010). However, whether any of these existing or unidentified substrates mediate the major function of Mule in the DNA damage response remains elusive.

In this study, by characterizing Mule knockout mouse embryonic fibroblasts (MEFs), we found that Mule is essential for DNA damage-induced p53 response and HDACiinduced apoptosis. HDACi administration could partially reverse these defects. Among HDACs, Mule specifically targets HDAC2 for ubiquitination and degradation. The cellular resistance to HDACis and defective p53 response in Mule-null cells could be fully rescued by lowering elevated HDAC2 protein levels to endogenous levels. Therefore, our results place Mule directly upstream of HDAC2 and suggest a critical role of this pathway in thecellular apoptotic response to HDACis and DNA damage.

\section{Results}

Mule is crucial for DNA damage-induced p53 acetylation, transcriptional activation, and apoptosis

Extensive DNA damage triggers apoptosis through a mitochondria-mediated intrinsic pathway. This principle is used by a class of chemotherapeutic drugs including Cisplatin to kill cancer cells. Accumulating biochemical and genetic evidence suggest a HECT domain ubiquitin ligase, Mule, is critical for the DNA damage response by controlling the ubiquitination and degradation of multiple substrates, although the phenotypes vary upon different cells/ tissues or inactivation approaches used (Chen et al. 2005; Zhong et al. 2005; Ross et al. 2011). In order to study the biological function of Mule, we generated a pair of isogenic Mule wild-type and knockout MEFs. In Mule knockout MEFs, Mule protein is completely absent (Supplemental Fig. S1). Of note, Mule wild-type and knockout cells show similar growth rates (Fig. 1A).

We determined the sensitivity of MEFs lacking Mule to killing by Cisplatin. Cisplatin is an alkylating agent that cross-links DNA. Mule ${ }^{-1-}$ cells are more resistant to Cisplatin than wild-type cells (Fig. 1B). Since p53 plays a pivotal role in DNA damage-induced apoptosis, we induced p53-mediated apoptosis by treating MEFs with Nutlin-3, a small molecular inhibitor that acts to inhibit MDM2 binding to 553 (Vassilev et al. 2004). Mule ${ }^{-1-}$ cells exhibit much stronger resistance to Nutlin-3 compared with wild-type cells (Fig. 1B). The biochemical analysis confirmed that caspase activation, represented by cleavage of two caspase substrates (PARP and caspase 3), is also delayed and attenuated in Mule ${ }^{-/-}$cells upon Cisplatin (Fig. 1C) or Nutlin-3 (Fig. 1D) treatments.

p53 accumulates and becomes active upon DNA damage by post-translational modifications, including acetylation and phosphorylation (Brooks and Gu 2003; Bode and Dong 2004). We determined whether stress-induced p53 modifications are affected in Mule-null cells. Mule ${ }^{+/+}$and Mule ${ }^{-/-}$ cells were treated with either Cisplatin or Nutlin-3. Levels of Ace-p53 (K373/K382) and phospho-p53 (S15) increase significantly in $\mathrm{Mule}^{+/+}$cells in a time-dependent manner upon both Cisplatin and Nutlin-3 treatment. In contrast, Ace-p53 and phospho-p53 fail to accumulate in $\mathrm{Mule}^{-/-}$ cells upon Cisplatin and Nutlin-3 treatment (Fig. 1E,F).

p53 acetylation has been shown to be critical for its transcriptional activity (Gu and Roeder 1997; Brooks and $\mathrm{Gu}$ 2003). We tested whether the lack of Mule affects p53 transcriptional activation. A panel of p53 transcriptional targets was examined in Mule wild-type and knockout cells. In Mule-null cells, p21, Mdm2, and Bax protein levels are dramatically reduced, while Bcl-2, the expression of which is inhibited by p53, is increased compared with Mule wild-type cells (Fig. 1G; Supplemental Fig. S2). The expression pattern of these p53 targets in Mule-null cells indicates a severe defect of p53 transcriptional activity. To consolidate this role of Mule in p53 transcriptional regulation, we used a luciferase assay in which luciferase expression was tightly controlled by tandem repeats of p53 response elements. In this assay, we found that p53 transcription activity in $\mathrm{Mule}^{-/-}$cells was significantly lower than that in Mule ${ }^{+/+}$cells (Fig. 1H). Coexpression of Mule with p53 dramatically enhanced p53-mediated luciferase activation compared with p53 alone (Fig. 1I). Collectively, these findings suggest that Mule positively regulates $\mathrm{p} 53$ acetylation and subsequent transcriptional activation. 
Zhang et al.

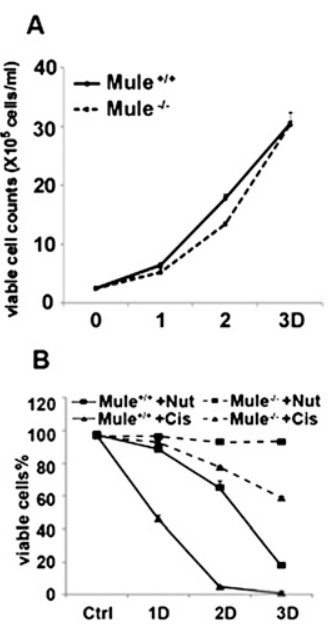

C

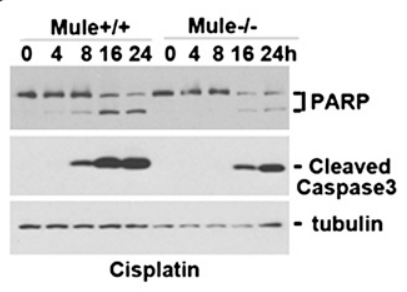

D Mule+1+ Mule-/-

$04816240481624 \mathrm{~h}$

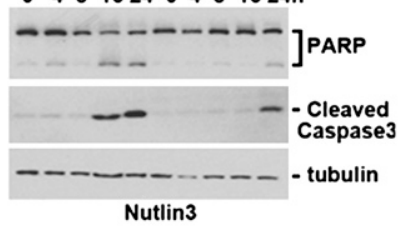

H

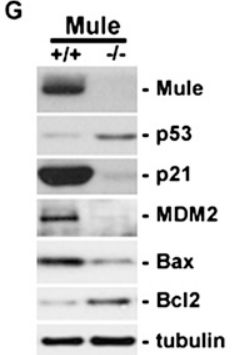

E

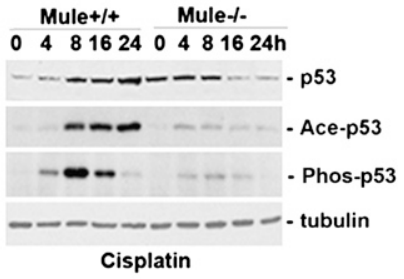

F Mule+1+ Mule-\%

$04816240481624 \mathrm{~h}$

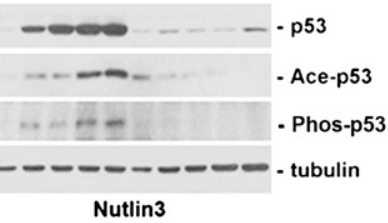

I

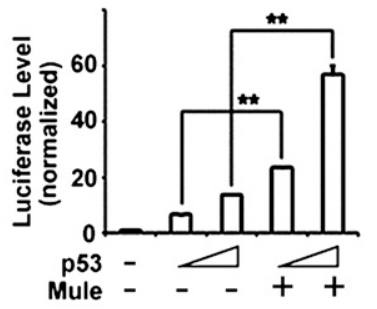

Figure 1. Mule is crucial for DNA damage-induced p53 acetylation, transcriptional activation, and apoptosis. $(A) \mathrm{Mule}^{+/+}$and Mule ${ }^{-/-}$ cells were seeded at the same concentration $\left(2.5 \times 10^{5}\right.$ cells per milliliter $)$ and counted by Trypan Blue staining at the time points indicated. $(B)$ Mule $^{+/+}$and Mule ${ }^{-/-}$cells were treated by Cisplatin $(20 \mu \mathrm{M})$ and Nutlin-3 $(10 \mu \mathrm{M})$ for the indicated times, then Trypan Blue staining was used to calculate the living versus dead cells. $(C, D)$ Caspase activation was analyzed by cleavage of caspase substrates PARP and caspase 3 upon Cisplatin $(C)$ and Nutlin-3 $(D)$ treatment as described in $B .(E, F)$. Mule ${ }^{+/+}$and Mule ${ }^{-/-}$MEFs were treated with $40 \mu \mathrm{M}$ Cisplatin $(E)$ or $10 \mu \mathrm{M}$ Nutlin-3 $(F)$ for the indicated times. p53 protein level, acetylation, and phosphorylation were analyzed. (G) Mule $^{+/+}$and Mule ${ }^{-/-}$MEFs were analyzed by Western Blotting to detect Mule, p53, p21, Mdm2, Bax, Bcl-2, and tubulin expression. (H) $\mathrm{Mule}^{+/+}$and Mule ${ }^{-/-}$MEFs were transfected by pGL3-p53-binding site-driven Luc and pSV40-Renilla. Folds of the relative Luciferase activities were normalized by pSV40-Renilla. (I) Mule ${ }^{-1-}$ MEFs were transfected by the indicated plasmids together with pGL3-p53-binding site-driven Luc and pSV40-Renilla. The relative p53-binding site Luc activity was normalized by pSV40-Renilla, and folds of increases against lane 1 were calculated. All experiments were repeated three times in triplicate. Data represent the mean \pm SD of all experiments.

\section{Mule is required for HDACi-induced apoptosis}

p53 was the first reported nonhistone substrate of HATs (Luo et al. 2000; Vaziri et al. 2001). p53 acetylation is removed by HDACs. HDAC1 has been shown to deacetylate p53 at Lys 373/382 to induce p21 expression (Zhao et al. 2006).p21 can also be activated by HDACis through p53-independent pathways (Gartel and Tyner 1999; Ocker and Schneider-Stock 2007). To investigate a potential role of HDACs in p53 defects presented in Mule-null cells, we treated Mule $\mathrm{M}^{+++}$and Mule $\mathrm{M}^{-/-}$cells with a series of HDACis and used p21 expression as a readout. Sodium butyrate $(\mathrm{NaBu})$, a class I/II HDACi, reverses p21 expression in Mule $^{-1-}$ cells (Fig. 2A). Two other HDACis, trichostatin A (TSA) (class I/II HDACi) and apicidin (class I HDACi), also at least partially rescue p21 expression in $\mathrm{Mule}^{-1-}$ cells (Supplemental Fig. S3). In contrast, a class III HDAC-specific inhibitor, nicotinamide, has no effect on p21 expression in Mule ${ }^{-/-}$cells (Fig. 2B).

The inability to acetylate p53 and the partial rescue by HDACis in Mule-null cells led us speculate that HDAC activity might be aberrantly elevated in the absence of Mule. The overactivation of HDACs might confer Muledeficient cell resistance to HDACi-induced apoptosis. HDACis have emerged as a promising therapeutic intervention in multiple malignancies, although the detailed mechanism of their cytotoxicity is still poorly understood. We determined the sensitivity of Mule knockout MEFs to killing by $\mathrm{NaBu}$ and vorinostat (SAHA), two mechanistically distinct HDACis. Mule ${ }^{-/-}$ cells are much more resistant to both $\mathrm{NaBu}$ and SAHA than wild-type cells (Fig. 2C). Additionally, caspase activation upon HDACi treatment is severely compromised in Mule $^{-/-}$cells compared with that in Mule wild-type cells (Fig. 2D,2E), indicating that Mule activity is crucial for HDACi-induced apoptosis.

\section{Mule controls HDAC2 stability}

The exact mechanism by which the HDACis may act in apoptosis is unclear. Given that Mule is a bona fide ubiquitin ligase, we speculate that Mule might regulate 
A

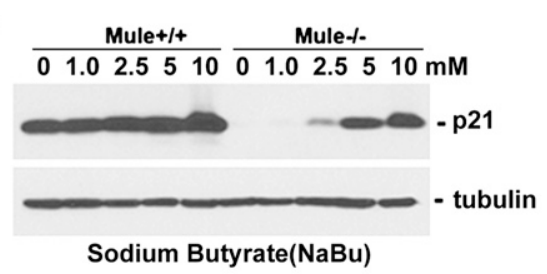

C

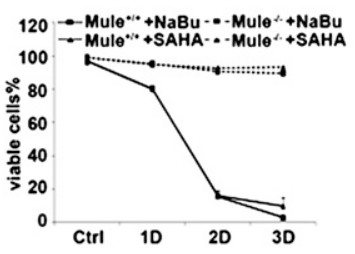

D Mule+l+ Mule- -
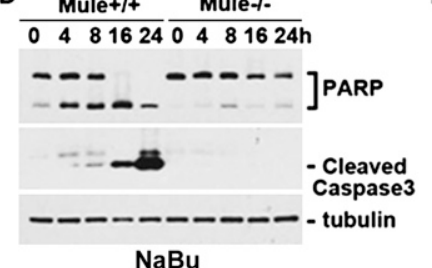

B

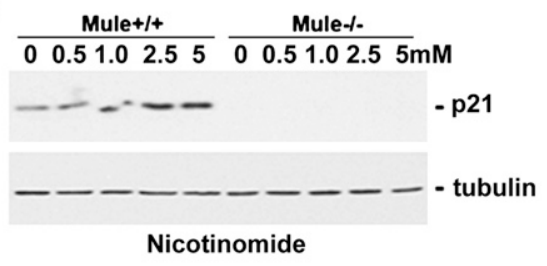

E

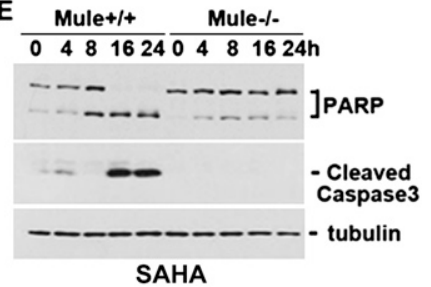

Figure 2. Mule is required for HDACi-induced apoptosis. $(A, B) \mathrm{Mule}^{+/+}$and Mule ${ }^{-/-}$MEFs were treated by indicated concentrations of HDACis $\mathrm{NaBu}(A)$ and nicotinomide $(B)$ for $24 \mathrm{~h}$. p21 expression levels were then detected in these cells. (C) HDACi NaBu (4 mM) or SAHA $(2.5 \mu \mathrm{M})$ was used to treat $\mathrm{Mule}^{+/+}$and $\mathrm{Mule}^{-/-}$cells, and Trypan Blue staining was used to calculate the living versus dead cells. $(D, E)$ Caspase activation was analyzed by cleavage of caspase substrates PARP and caspase 3 upon NaBu $(4 \mathrm{mM})$ or SAHA (2.5 $\mu \mathrm{M})$ treatment.

the abundance of HDACs to control the cellular response to HDACis. A panel of HDAC family proteins was screened for their expression in Mule wild-type and knockout cells. As depicted in Figure 3A, levels of HDAC2 were clearly increased in Mule $\mathrm{M}^{--}$cells and HDAC4 was slightly decreased, while the rest of HDACs tested had no detectable change in either Mule He $^{+/}$or Mule ${ }^{-/-}$cells. Of note, there is no remarkable change in HDAC2 mRNA level in the absence of Mule (Fig. 3B), suggesting that HDAC2 protein accumulates in $\mathrm{Mule}^{-/-}$cells. To test that the HDAC2 accumulation in the absence of Mule is not cell typespecific, we also depleted Mule in human lung adenocarcinoma epithelial A549 cells by shRNA expression. In A549 cells, HDAC2 accumulates when Mule is depleted (Fig. 3C). Consequently, these data suggest that Mule negatively regulates HDAC2 protein level.

We further investigated whether HDAC2 accumulation in Mule knockout MEFs could be reversed by Mule expression. Different levels of Mule were ectopically expressed in Mule $^{-/-}$cells. Expression of Flag-tagged full-length Mule causes a marked reduction in the levels of endogenous HDAC2 but not HDAC1 in Mule ${ }^{-/-}$cells (Fig. 3D).

We measured the half-life of HDAC2 in Mule wild-type and knockout MEFs to assess whether Mule affects HDAC2 stability. Using cycloheximide, an inhibitor of new protein synthesis, the half-life of residual HDAC2 was determined. Compared with Mule ${ }^{+/+}$cells, HDAC2 protein half-life is prolonged in Mule ${ }^{-/-}$cells (Fig. 3E). In contrast, in the same experiment, we found that $\mathrm{HDACl}$ half-life was not altered in Mule ${ }^{-/-}$cells. Based on these observations, we conclude that Mule specifically controls HDAC2 stability.

\section{Mule binds and ubiquitinates HDAC2}

Mule is a HECT domain-containing ubiquitin ligase that ubiquitinates and degrades multiple cellular substrates (Adhikary et al. 2005; Chen et al. 2005; Hall et al. 2007; Liu et al. 2007; Herold et al. 2008; Zhao et al. 2008; Parsons et al. 2009; Yang et al. 2010). We speculated that HDAC2 is a Mule ubiquitination substrate. First, we tested HDAC2 binding to Mule in vivo and in vitro. HDAC2 coimmunoprecipitates with Mule in vivo (Fig. 4A). Remarkably, this interaction is significantly increased upon $\mathrm{NaBu}$ treatment (Fig. 4B), despite the fact that Mule expression remains largely unchanged upon $\mathrm{NaBu}$ treatment (Supplemental Fig. S4). To detect direct binding between Mule and HDAC2, we expressed and purified full-length Mule from baculovirus-infected insect cells and HDAC2 from transfected HEK293T cells to near homogeneity (Supplemental Fig. S5). In an in vitro binding assay with only purified recombinant Mule and HDAC2, a clear association between these two proteins was detected (Fig. 4C). Hence, our data indicate that HDAC2 directly interacts with Mule.

Since polyubiquitination is required for protein degradation, we tested whether Mule catalyzes HDAC2 polyubiquitination in vitro and in vivo. In the in vitro ubiquitination assay with recombinant E1, E2 (Ubc5 or Ubc7), and E3 (full-length Mule), Mule strongly promotes HDAC2 ubiquitination in a dose-dependent manner (Fig. 4D). To further confirm that HDAC2 is polyubiquitinated, we employed a FK2 antibody that specifically recognizes polyubiquitin chains. In the presence of Mule, a high molecular mass of HDAC2, indicative of polyubiquitin modification, was detected by FK2, demonstrating that HDAC2 is polyubiquitinated by Mule (Fig. 4E). To verify that the ubiquitination of HDAC2 by Mule is specific, NRBF2, an autophagy-related protein that is unrelated to this process, was also tested in the in vitro ubiquitination assay. As shown in Figure 4E (lanes 3,4), NRBF2 cannot be ubiquitinated by full-length Mule.

We also investigated whether Mule is necessary for HDAC2 ubiquitination in vivo. To do this, we transfected A549 cells stably expressing Mule shRNA and the control cell line with Flag-HDAC2, followed by MG132 treatment. HDAC2 ubiquitination was significantly attenuated in Mule knockdown cells compared with the control cell 


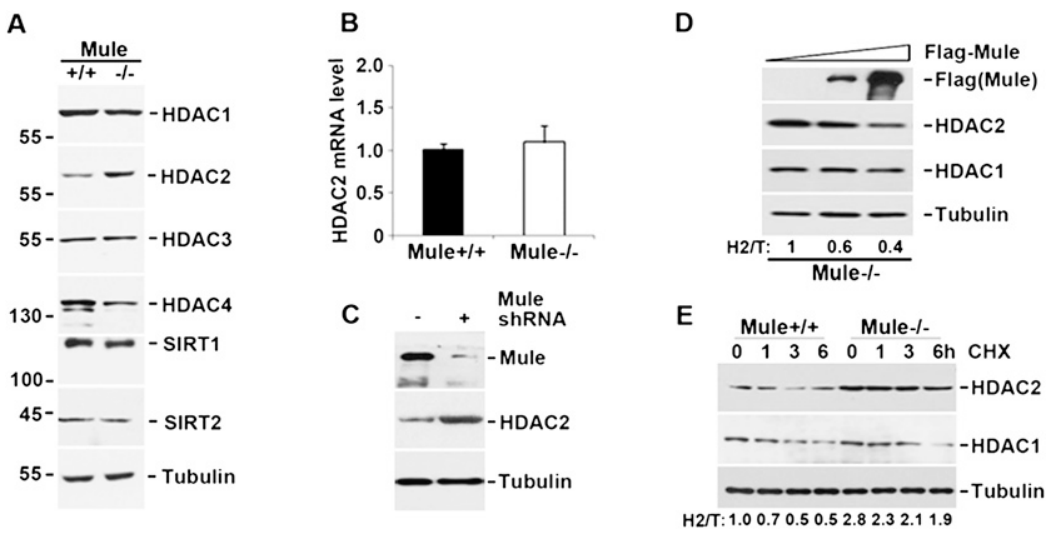

Figure 3. Mule negatively regulates HDAC2 stability. (A) A subset of HDAC family proteins was detected in $\mathrm{Mule}^{+/+}$and Mule ${ }^{-/-}$MEFs by Western blotting using individual antibodies as indicated with $\beta$-tubulin as a loading control. $(B)$ HDAC2 mRNA levels were detected by quantitative RT-PCR in $\mathrm{Mule}^{+/+}$and $\mathrm{Mule}^{-/-}$MEFs and plotted after normalization. $(C)$ Mule was knocked down by shRNA in the human lung adenocarcinoma epithelial cell line A549 for HDAC2 detection. (D) Mule $^{-/-}$MEFs were transfected with increasing amounts of pCDNA4Flag-Mule plasmids or the empty vectors; $24 \mathrm{~h}$ later, protein levels of HDAC1 and HDAC2 were measured. (E) $\mathrm{Mule}^{+/+}$and $\mathrm{Mule}^{-/-}$cells were treated with or without $60 \mu \mathrm{g} / \mathrm{mL}$ cycloheximide (CHX) for the indicated times. The ratio of HDAC2/Tubulin in $D$ and $E$ is shown as $\mathrm{H} 2 / \mathrm{T}$. line (Fig. 4F). Together, these data demonstrate that Mule physically interacts with HDAC2 and promotes its ubiquitination.

\section{HDAC2 links Mule to DNA damage and HDACi-induced apoptosis}

We next investigated the significance of the HDAC2 regulation by Mule in DNA damage- and HDACi-induced apoptosis. Mule targets multiple substrates, including Mcl-1, for degradation upon DNA damage, and more than one HDAC are inhibited by HDACis. We did observe that
HDAC2 is specifically accumulated in Mule-null cells. If this is the causative factor for the cell death defects, we expect the defects to be restored when the protein levels of HDAC2 are reduced to the normal levels in the wild-type cells. To test this hypothesis, we generated stable cell lines in Mule $^{-/-}$cells that express shRNA against HDAC2 or vector alone as a control. We first examined the expression of HDAC2 in these cell lines to ensure that the expression of HDAC2 is down-regulated to levels comparable with the endogenous HDAC2 levels as in wild-type cells (Fig. 5A). Then the response to both DNA damage- and HDACiinduced apoptosis was analyzed in these three cell lines.
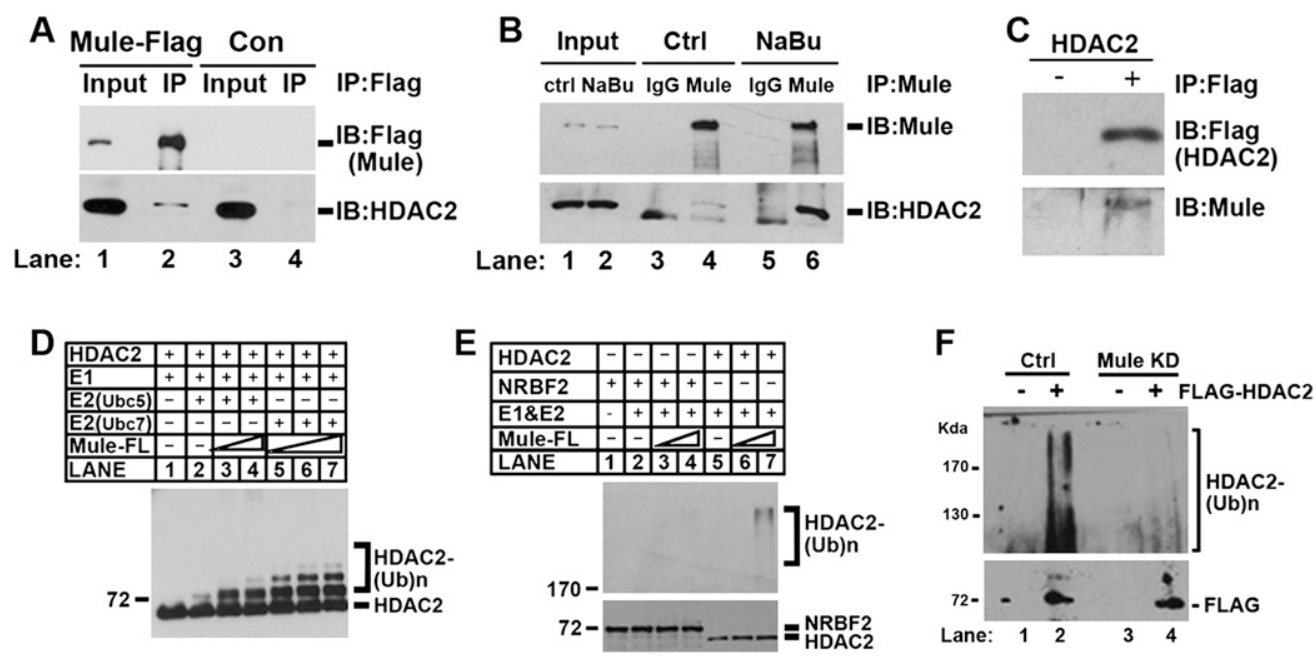

Figure 4. Mule binds and ubiquitinates HDAC2. (A) HEK293T cell lines stably expressing Flag-Mule were immunoprecipitated (IP) with anti-Flag M2 beads. Proteins bound to beads and the experimental inputs $(5 \%)$ were probed with anti-Flag and anti-HDAC2. (B)

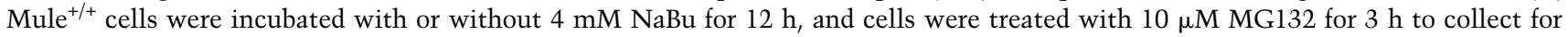
immunoprecipitation using Mule antibody, with normal mouse IgG as negative control. Mule or HDAC2 was detected by Western blotting. $(C)$ Purified recombinant Flag-HDAC2 $(500 \mathrm{nM})$ was incubated with His-Mule $(200 \mathrm{nM})$ and analyzed in an in vitro pull-down assay. $(D)$ Recombinant HDAC2 (100 nM) was incubated with ATP regenerating buffer, E1, E2 (Ubc5 and Ubc7), recombinant HIS-Mule $(10 \mathrm{nM}, 40 \mathrm{nM}$, or $80 \mathrm{nM})$, and ubiquitin in a $10-\mu \mathrm{L}$ reaction volume for $1 \mathrm{~h}$ at $37^{\circ} \mathrm{C}$. $(E)$ HDAC2 ubiquitination reactions were performed in the presence of E1, E2 (Ubc7), and E3 (full-length Mule) to visualize polyubiquitin chain formation. The reaction mixture was subjected to immunoprecipitation by anti-Flag M2 beads followed by Western blotting with FK2 antibody. Recombinant Flag-GSTtagged NRBF2 (200 nM) was used as a negative control in the ubiquitination reaction. (F) Mule knockdown A549 cells as well as control cells were transfected with Flag-HDAC2; $24 \mathrm{~h}$ later, cells were treated by $10 \mu \mathrm{M}$ MG132 for $3 \mathrm{~h}$ and then collected for immunoprecipitation using anti-Flag M2 beads, followed by Western blotting using FK2 antibody. 

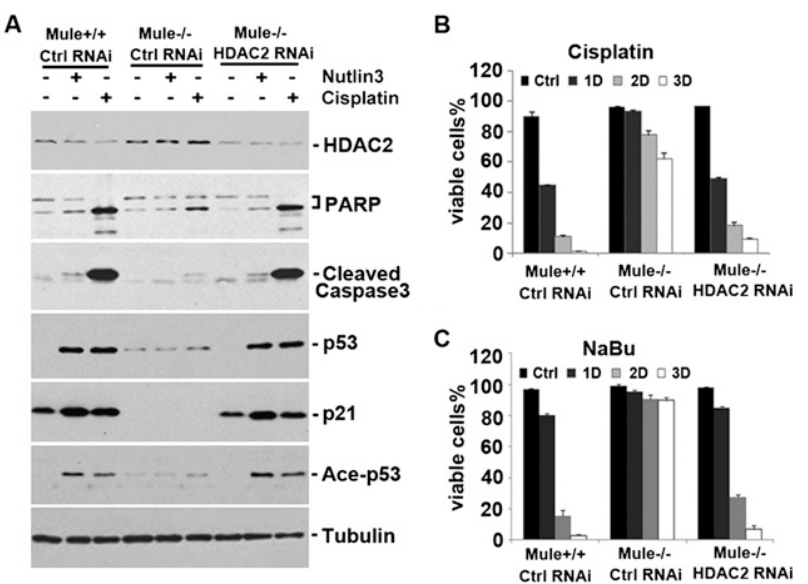

Figure 5. Correction of Mule-null phenotype by HDAC2 knockdown. (A) HDAC2 was knocked down in Mule ${ }^{-/-}$cells using specific shRNA against HDAC2. HDAC2 knockdown efficiency; cleavage of caspase substrates; and p53 accumulation, acetylation, and transcriptional activation shown as p21 expression were determined upon treatment of $40 \mu \mathrm{M}$ Cisplatin or $10 \mu \mathrm{M}$ Nutlin-3. $(B, C) \mathrm{Mule}^{+/+}, \mathrm{Mule}^{-/-}$, and Mule ${ }^{-/-}$cells with HDAC2 depletion were treated with $20 \mu \mathrm{M}$ Cisplatin $(B)$ or $4 \mathrm{mM} \mathrm{NaBu}(C)$ for the indicated times. Trypan Blue Exclusion assay was used to calculate the living versus dead cells in these cells upon Cisplatin and $\mathrm{NaBu}$ treatment.

Remarkably, lowering the HDAC2 level to a near wild-type level in Mule $^{-/-}$cells is sufficient to restore cellular sensitivity to Cisplatin (Fig. 5A,B). In addition, reducing HDAC2 in $\mathrm{Mule}^{-/-}$cells also resensitized these cells to HDACis (Fig. 5C). Furthermore, both caspase 3 and PARP cleavage upon Cisplatin treatment in $\mathrm{Mule}^{-/-}$cells are restored to levels similar to that in $\mathrm{Mule}^{+/+}$cells when HDAC2 level is lowered (Fig. 5A). Finally, reducing HDAC2 to normal levels is enough to restore p53 accumulation, acetylation, and transcriptional activation upon stress in Mule $^{-/-}$cells (Fig. 5A).

Mule also targets Mcl-1 for ubiquitination and degradation (Zhong et al. 2005). We further investigated whether Mcl-1 accumulation contributes to cellular resistance to DNA damage- and HDACi-induced apoptosis in Mule-null cells. Consistent with the previous report (Zhong et al. 2005), Mcl-1 is rapidly degraded upon Cisplatin treatment; this degradation is compromised in the absence of Mule. The turnover of HDAC2 upon Cisplatin treatment is not altered in the presence or absence of Mule (Fig. 6A). In contrast, upon $\mathrm{NaBu}$ treatment, HDAC2 is degraded quickly and the degradation is clearly blocked in Mule-null cells, while Mcl-1 is rather stable. These observations suggest that Mule likely targets different substrates for destruction upon distinct apoptotic stimuli. Consistently, reduction of Mcl-1 protein level to the wild-type level failed to resensitize Mule-null cells to HDACi treatment as HDAC2 knockdown (Fig. 6C,D), while it partially rescued the cellular sensitivity to Cisplatin treatment (Supplemental Fig. S6A,B).

To further consolidate the specific effect of HDAC2 in Mule-null cells, we also depleted HDAC4 protein, another HDAC family member that is shown to be involved in the DNA damage response (Kao et al. 2003), in Mule-null cells by the RNAi approach. Depletion of HDAC4 in Mule-null cells also leads to partial rescue of cellular resistance to Cisplatin treatment (Supplemental Fig. S6C,D), which is consistent with its reported role in the DNA damage response (Kao et al. 2003). However, HDAC4 depletion has little effect on the cellular resistance of Mule-null cells to HDACis (Fig. 6E,F), suggesting that HDAC2 plays a specific and essential role in Mule-dependent HDACiinduced apoptosis.

\section{Discussion}

The signaling pathways that activate cell death induced by HDACis are of crucial interest, and in this study, we provide genetic evidence that Mule is a pivotal regulator of both DNA damage- and HDACi-induced apoptosis. This regulation is achieved by Mule through direct interaction and ubiquitination of HDAC2. By lowering the accumulated HDAC2 in Mule knockout cells, the defective p53 acetylation, accumulation, transcriptional activity, and apoptosis upon stress are completely reversed. Thus, we defined a unique molecular mechanism for regulation of HDAC2 and apoptosis induced by DNA damage and HDACis. By identifying Mule as a crucial ubiquitin ligase that controls HDAC2 stability, we also elucidate a mechanism for resistance to DNA damage and HDACi chemotherapeutics. Since the multidrug resistance mediated by efflux mechanisms does not seem to constitute a major driver of tumor cell resistance to HDACis, down-regulation or inactivation of Mule could constitute a reason for HDACi resistance.

HDAC2, as a member of class I HDACs that functions to remove the acetyl group from either histones or other proteins (Finnin et al. 1999; Grozinger et al. 1999), carries out critical regulatory function in expression of multiple genes, and its activity is tightly regulated by several mechanisms (Kramer 2009). It is still not clear how Mule specifically targets HDAC2 for destruction. Without Mule, there is no clear accumulation of HDAC1, and HDAC4 is even decreased. The detailed mechanism of these differential regulations remains to be solved. One possibility is that HDAC2 is distinct from other HDAC members by post-translational modifications. It has been shown that HDAC2 protein is regulated by lysine ubiquitination, serine phosphorylation, tyrosine nitration, and cysteine nitrosylation (Sun et al. 2002; Kramer et al. 2003; Nott et al. 2008; Adenuga et al. 2009; Brandl et al. 2009; Osoata et al. 2009). Other ubiquitin conjugation and ligation enzymes have also been implicated in HDAC2 destruction. Valproic acid (VPA), a class I HDACi, induced HDAC2 degradation by the ubiquitin-proteasome pathway, which is dependent on the E2 ubiquitin conjugase Ubc8 and the E3 ubiquitin ligase RLIM (Kramer et al. 2003). However, it seems that these enzymes only function in the VPA-induced HDAC2 destruction rather than in more general settings.

Overexpression of HDAC2 leads to a strong inhibition of synaptogenesis and memory loss in affected animals (Akhtar et al. 2009; Guan et al. 2009). Coincidently, a homolog of Mule in Caenorhabditis elegans has also been isolated from a genetic screen as a crucial factor required for synaptogenesis in worms (Sieburth et al. 2005). It will be interesting 
A

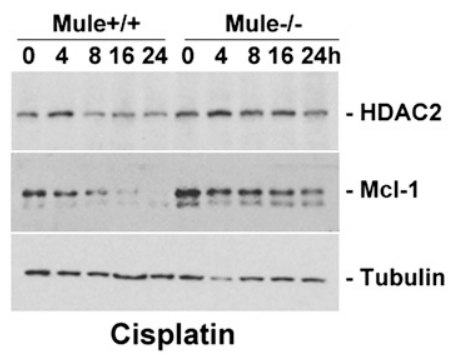

C

Mule + /+ Mule $\%$ Mule $/$ - Mule $/$ Ctrl RNAi Ctrl RNAi H2 RNAi Mcl-1RNAi $\frac{C \text { trI RNA }}{-+-+-} \frac{\text { tri RNAi }}{-++-}$ NaBu

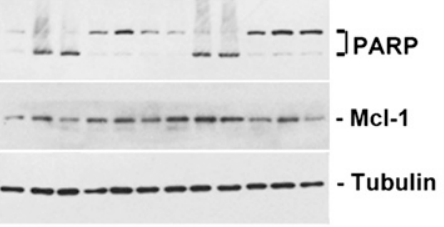

E Mule+/+ Mule $/$ - Mule $-\%$ Mule $/$ Ctrl RNAi Ctrl RNAi H2 RNAi H4 RNAi $++-\frac{-}{-+-}++\mathrm{NaBu}$ $-+\cdot++\cdot+\cdot++\mathrm{SAHA}$

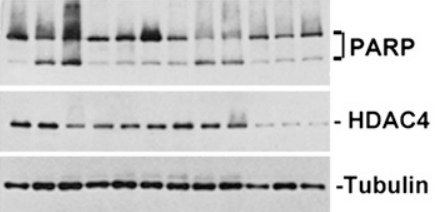

B

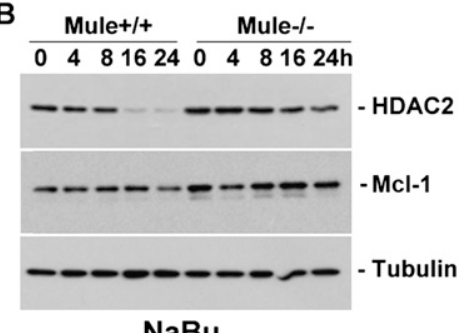

NaBu

D

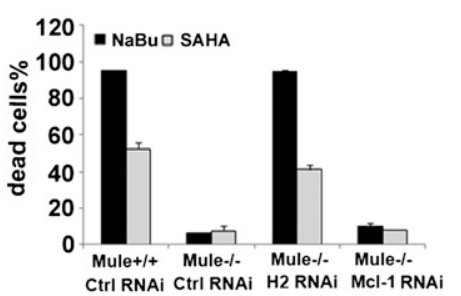

$\mathbf{F}$

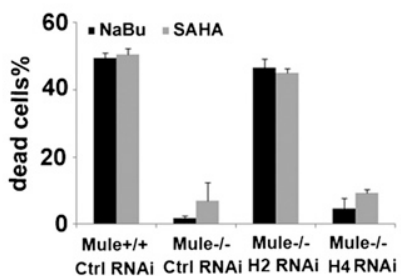

Figure 6. Differential regulation of $\mathrm{HDAC2}$, Mcl-1, and HDAC4 by Mule upon HDACi treatment. $(A, B)$ HDAC2, Mcl-1, and tubulin were detected by Western blotting at the indicated time points after $40 \mu \mathrm{M}$ Cisplatin $(A)$ or $4 \mathrm{mM} \mathrm{NaBu}(B)$ treatment. $(C)$ Mule $^{+/+}$, Mule $^{-/-}$, and Mule M $^{-/-}$cells with HDAC2 (H2) knockdown and Mule ${ }^{-/-}$cells with Mcl-1 knockdown were treated with $4 \mathrm{mM} \mathrm{NaBu}$ or 2.5 $\mu \mathrm{M}$ SAHA, cleaved PARP, Mcl-1, and tubulin, and probed by Western blotting. $(D)$ The same cell lines described in $C$ were treated with $4 \mathrm{mM} \mathrm{NaBu}$, or 2.5 $\mu \mathrm{M}$ SAHA. Trypan Blue Exclusion assay was used to calculate the dead versus living cells in these cells. $(E, F) \mathrm{Mule}^{+/+}, \mathrm{Mule}^{-/-}, \mathrm{Mule}^{-/-}$cells with HDAC2 (H2) knockdown and $\mathrm{Mule}^{-/-}$cells with HDAC4 (H4) knockdown were treated with $4 \mathrm{mM} \mathrm{NaBu}$ or $2.5 \mu \mathrm{M}$ SAHA, and PARP cleavage $(E)$ and cell death by Trypan Blue Exclusion assay $(F)$ were analyzed in these cells. to further test whether Mule regulates synaptogenesis via its proteasomal degradation of HDAC2 in synaptogenesis and memory formation and how this pathway is involved in human neurodegeneration diseases. HDAC2 levels are also reduced in COPD (Barnes 2005, 2009). As a ubiquitin ligase of HDAC2, whether Mule contributes to this pathological condition is also of great interest.

In conclusion, this study provides a molecular link connecting Mule, HDAC2, and apoptosis. Mule directly ubiquitinates HDAC2 and targets it for proteasomal degradation. Manipulating Mule activity by chemical means is probably a crucial strategy for multiple human diseases. We show here that the Mule-HDAC2 axis acts on the p53 pathway to regulate its activity in the DNA damage response. The role of Mule-HDAC2 in p53 regulation might suggest a previous unrealized important function in tumor suppression. Besides, Mule-HDAC2 might also regulate apoptosis and gene expression through p53-independent pathways. Importantly, targeting these pathways through these newly discovered regulators might bring novel therapeutic tools against cancer.

\section{Materials and methods}

\section{Reagents}

$\mathrm{Mule}^{+/+}$and Mule ${ }^{-/-}$MEFs, together with HEK293T and A549 cells, were cultured in DMEM supplemented with $10 \%$ FBS pCDNA5/FRT/TO and pCDNA4/TO (Invitrogen) were modified as previously described (Sun et al. 2008, 2010a). The Mule coding sequence was inserted between BamHI and NotI sites to generate the reading frame of Mule-Flag, which was used for establishing stable cell lines. pME18sFL3-HDAC2 was a gift from Dr. Ed Seto (H. Lee Moffitt Cancer Center and Research Institute, FL). Cisplatin and Nutlin-3 were purchased from Sigma and Cayman Chemical, respectively. HDACis $\mathrm{NaBu}$, TSA, and apicidin were purchased from Sigma. SAHA was purchased from Selleck Chemicals Co. Nicotinomide was kindly provided by Dr. Danica Chen (University of California at Berkeley).

\section{Generation of shRNA cell lines}

For Mule knockdown cell lines, shRNA lentiviral particles for human Mule were purchased from Santa Cruz Biotechnologies and used to establish a stable shRNA cell line in A549 cells according to the manufacturer. For HDAC2, Mcl-1, and HDAC4 knockdown, the shRNA sequences were designed with siRNA Target Finder (Ambion) and cloned into BglII and HindIII sites of pSUPER.retro. neo+GFP vector (OligoEngine). The knockdown stable cell lines were generated from Mule ${ }^{-1-}$ MEF cells according to the manufacturer. The shRNA coding sequence for mouse HDAC2 knockdown was GATCCCCCTTGCCATTGCTGATGCTCTTCAAGA GAGAGCATCAGCAATGCAAGTTTTTA, with the targeted sequence of HDAC2 in italics. The targeted sequences for mouse Mcll and HDAC4 were GGCGGCATCAGAAATGTGC and CTCCTAGCACTGAAACAGA separately.

\section{Production of recombinant proteins}

The protocol for producing recombinant proteins from insect cells was the same as the tandem affinity purification (TAP) procedure described before (Sun et al. 2010a). For recombinant proteins 
purified from mammalian cells, the method was adopted from the previously mentioned TAP protocol as follows: $293 \mathrm{~T}$ cells were cultured in DMEM supplemented with $10 \%$ FBS. When the cell confluency rose to $80 \%-90 \%$, cell transfection was performed using PEI solution (30- $\mu \mathrm{g}$ per 15-cm dish). Two days after transfection, whole-cell lysates (WCLs) were prepared in TAP buffer $(20 \mathrm{mM}$ Tris $\mathrm{HCl}$ at $\mathrm{pH} 7.5,150 \mathrm{mM} \mathrm{NaCl}, 0.5 \%$ Nonidet P-40, $1 \mathrm{mM} \mathrm{NaF}, 1 \mathrm{mM} \mathrm{Na}_{3} \mathrm{VO}_{4}, 1 \mathrm{mM}$ EDTA, protease inhibitor mixture [Roche]) and recombinant proteins were pulled down using anti-Flag beads. Before elution, the beads with recombinant proteins were given three washes using high-salt buffer ( $20 \mathrm{mM}$ Tris $\mathrm{HCl}$ at $\mathrm{pH} 7.5,650 \mathrm{mM} \mathrm{NaCl}, 0.5 \%$ Nonidet P-40). The proteins were finally eluted using Flag peptide solution and analyzed by SDS-PAGE.

\section{In vitro ubiquitination assay}

Recombinant full-length HIS-Mule was purified from baculovirus insect cells, and recombinant Flag-HDAC2 protein was purified from transfected HEK293T cells as previously described (Zhong et al. 2005; Sun et al. 2010a,b). For the in vitro ubiquitination assay, $100 \mathrm{nM}$ recombinant Flag-HDAC2 was incubated in a $15-\mu \mathrm{L}$ reaction with an ATP regenerating system $(50 \mathrm{mM}$ Tris at $\mathrm{pH} 7.6,5 \mathrm{mM} \mathrm{MgCl}_{2}, 2 \mathrm{mM}$ ATP, $10 \mathrm{mM}$ creatine phosphate, 3.5 $\mathrm{U} / \mathrm{mL}$ creatine kinase), $10 \mathrm{ng}$ of human E1, $100 \mathrm{ng}$ of Ubc5/7, $2 \mu \mathrm{M}$ ubiquitin aldehyde, and 10, 40, and $80 \mathrm{nM}$ full-length Mule for $1 \mathrm{~h}$ at $37^{\circ} \mathrm{C}$. After terminating the reactions with SDS sample buffer, reaction products were fractionated by SDS-PAGE $(7.5 \%)$ and analyzed by Western blotting with anti-Flag M2 antibody during purification. To detect the polyubiquitin chain, the reaction mixture was then incubated with $3 \mu \mathrm{L}$ of anti-Flag (M2) beads, washed with buffer A $(20 \mathrm{mM}$ HEPES at $\mathrm{pH} 7.5,10 \mathrm{mM}$ $\mathrm{KCl}, 1.5 \mathrm{mM} \mathrm{MgCl}_{2}, 1 \mathrm{mM}$ EDTA, 1 mM EGTA, $1 \mathrm{mM}$ DTT, 0.1 $\mathrm{mM}$ PMSF) three times, and subjected to SDS-PAGE $(6 \%)$ and immunoblotting with anti-FK2 antibody (Biomol).

\section{Statistical analysis}

All experiments were repeated at least three times, and similar results were obtained. All values represent means, with the error bars in the figures indicating the standard deviation of triplicates in an independent experiment. A $t$-test was used to compare the statistical difference between two groups. A value of $P<0.05$ is considered to be statistically significant.

Please see the Supplemental Material for more Materials and Methods.

\section{Acknowledgments}

We thank all Zhong laboratory members for helpful discussion and technical assistance. We also thank Ed Seto, Danica Chen, Tara Tracy, and Lu Chen for reagents, and Livia Wilz for the critical reading of the manuscript. The work is supported by a New Investigator Award for Aging from the Ellison Medical Foundation, Hellman Family Fund, American Cancer Society Research Scholar Grant (RSG-11-274-01-CCG), and NIH RO1 (CA133228) to Q.Z. J.Z. performed the majority of the experiments, with contributions from S.K. and B.H.. Z.H. and M.T. generated the Mule $^{+/+}$and Mule ${ }^{-/-}$MEFs. J.Z. and Q.Z. wrote the manuscript. Q.Z. directed the work. All authors discussed the results and commented on the manuscript.

\section{References}

Adenuga D, Yao H, March TH, Seagrave J, Rahman I. 2009. Histone deacetylase 2 is phosphorylated, ubiquitinated, and degraded by cigarette smoke. Am J Respir Cell Mol Biol 40: 464-473.

Adhikary S, Marinoni F, Hock A, Hulleman E, Popov N, Beier R, Bernard S, Quarto M, Capra M, Goettig S, et al. 2005. The ubiquitin ligase HectH9 regulates transcriptional activation by Myc and is essential for tumor cell proliferation. Cell 123: 409-421.

Akhtar MW, Raingo J, Nelson ED, Montgomery RL, Olson EN, Kavalali ET, Monteggia LM. 2009. Histone deacetylases 1 and 2 form a developmental switch that controls excitatory synapse maturation and function. J Neurosci 29: 8288-8297.

Balakin KV, Ivanenkov YA, Kiselyov AS, Tkachenko SE. 2007. Histone deacetylase inhibitors in cancer therapy: latest developments, trends and medicinal chemistry perspective. Anticancer Agents Med Chem 7: 576-592.

Barnes PJ. 2005. Targeting histone deacetylase 2 in chronic obstructive pulmonary disease treatment. Expert Opin Ther Targets 9: 1111-1121.

Barnes PJ. 2009. Role of HDAC2 in the pathophysiology of COPD. Annu Rev Physiol 71: 451-464.

Beckerman R, Prives C. 2010. Transcriptional regulation by p53. Cold Spring Harb Perspect Biol 2: a000935. doi: 10.1101/ schperspect.a000935.

Blander G, Guarente L. 2004. The Sir2 family of protein deacetylases. Annu Rev Biochem 73: 417-435.

Bode AM, Dong Z. 2004. Post-translational modification of p53 in tumorigenesis. Nat Rev Cancer 4: 793-805.

Brandl A, Heinzel T, Kramer OH. 2009. Histone deacetylases: salesmen and customers in the post-translational modification market. Biol Cell 101: 193-205.

Brooks CL, Gu W. 2003. Ubiquitination, phosphorylation and acetylation: the molecular basis for $\mathrm{p} 53$ regulation. Curr Opin Cell Biol 15: 164-171.

Chen D, Kon N, Li M, Zhang W, Qin J, Gu W. 2005. ARF-BP1/ Mule is a critical mediator of the ARF tumor suppressor. Cell 121: 1071-1083.

Choudhary C, Kumar C, Gnad F, Nielsen ML, Rehman M, Walther TC, Olsen JV, Mann M. 2009. Lysine acetylation targets protein complexes and co-regulates major cellular functions. Science 325: 834-840.

de Ruijter AJ, van Gennip AH, Caron HN, Kemp S, van Kuilenburg AB. 2003. Histone deacetylases (HDACs): characterization of the classical HDAC family. Biochem $J$ 370: 737-749.

Feng L, Lin T, Uranishi H, Gu W, Xu Y. 2005. Functional analysis of the roles of posttranslational modifications at the p53 C terminus in regulating p53 stability and activity. Mol Cell Biol 25: 5389-5395.

Finnin MS, Donigian JR, Cohen A, Richon VM, Rifkind RA, Marks PA, Breslow R, Pavletich NP. 1999. Structures of a histone deacetylase homologue bound to the TSA and SAHA inhibitors. Nature 401: 188-193.

Gartel AL, Tyner AL. 1999. Transcriptional regulation of the p21 (WAF1/CIP1) gene. Exp Cell Res 246: 280-289.

Glozak MA, Sengupta N, Zhang X, Seto E. 2005. Acetylation and deacetylation of non-histone proteins. Gene 363: 15-23.

Grozinger CM, Hassig CA, Schreiber SL. 1999. Three proteins define a class of human histone deacetylases related to yeast Hdalp. Proc Natl Acad Sci 96: 4868-4873.

$\mathrm{Gu}$ W, Roeder RG. 1997. Activation of p53 sequence-specific DNA binding by acetylation of the p53 C-terminal domain. Cell 90: 595-606.

Guan JS, Haggarty SJ, Giacometti E, Dannenberg JH, Joseph N, Gao J, Nieland TJ, Zhou Y, Wang X, Mazitschek R, et al. 2009. HDAC2 negatively regulates memory formation and synaptic plasticity. Nature 459: 55-60. 
Haberland M, Montgomery RL, Olson EN. 2009. The many roles of histone deacetylases in development and physiology: implications for disease and therapy. Nat Rev Genet 10: 32-42.

Hall JR, Kow E, Nevis KR, Lu CK, Luce KS, Zhong Q, Cook JG. 2007. Cdc6 stability is regulated by the Huwe1 ubiquitin ligase after DNA damage. Mol Biol Cell 18: 3340-3350.

Herold S, Hock A, Herkert B, Berns K, Mullenders J, Beijersbergen R, Bernards R, Eilers M. 2008. Mizl and HectH9 regulate the stability of the checkpoint protein, TopBP1. EMBO I 27: 2851-2861.

Kao GD, McKenna WG, Guenther MG, Muschel RJ, Lazar MA, Yen TJ. 2003. Histone deacetylase 4 interacts with 53BP1 to mediate the DNA damage response. I Cell Biol 160: 1017-1027.

Kramer OH. 2009. HDAC2: a critical factor in health and disease. Trends Pharmacol Sci 30: 647-655.

Kramer OH, Zhu P, Ostendorff HP, Golebiewski M, Tiefenbach J, Peters MA, Brill B, Groner B, Bach I, Heinzel T, et al. 2003. The histone deacetylase inhibitor valproic acid selectively induces proteasomal degradation of HDAC2. EMBO I 22: 3411-3420.

Lakin ND, Jackson SP. 1999. Regulation of p53 in response to DNA damage. Oncogene 18: 7644-7655.

LeBoeuf M, Terrell A, Trivedi S, Sinha S, Epstein JA, Olson EN, Morrisey EE, Millar SE. 2010. Hdac1 and Hdac2 act redundantly to control p63 and p53 functions in epidermal progenitor cells. Dev Cell 19: 807-818.

Levine AJ. 1997. p53, the cellular gatekeeper for growth and division. Cell 88: 323-331.

Li M, Luo J, Brooks CL, Gu W. 2002. Acetylation of p53 inhibits its ubiquitination by Mdm2. J Biol Chem 277: 50607-50611.

Liu Z, Miao D, Xia Q, Hermo L, Wing SS. 2007. Regulated expression of the ubiquitin protein ligase, E3(Histone)/LASU1/Mule/ ARF-BP1/HUWE1, during spermatogenesis. Dev Dyn 236: 2889-2898.

Luo J, Su F, Chen D, Shiloh A, Gu W. 2000. Deacetylation of p53 modulates its effect on cell growth and apoptosis. Nature 408: $377-381$.

Menendez D, Inga A, Resnick MA. 2009. The expanding universe of p53 targets. Nat Rev Cancer 9: 724-737.

Mottet D, Castronovo V. 2008. Histone deacetylases: target enzymes for cancer therapy. Clin Exp Metastasis 25: 183-189.

Nott A, Watson PM, Robinson JD, Crepaldi L, Riccio A. 2008. S-Nitrosylation of histone deacetylase 2 induces chromatin remodelling in neurons. Nature 455: 411-415.

Ocker M, Schneider-Stock R. 2007. Histone deacetylase inhibitors: signalling towards p21cip1/waf1. Int J Biochem Cell Biol 39: $1367-1374$.

Osoata GO, Yamamura S, Ito M, Vuppusetty C, Adcock IM, Barnes PJ, Ito K. 2009. Nitration of distinct tyrosine residues causes inactivation of histone deacetylase 2. Biochem Biophys Res Commun 384: 366-371.

Parsons JL, Tait PS, Finch D, Dianova II, Edelmann MJ, Khoronenkova SV, Kessler BM, Sharma RA, McKenna WG, Dianov GL. 2009. Ubiquitin ligase ARF-BP1/Mule modulates base excision repair. EMBO I 28: 3207-3215.

Robert T, Vanoli F, Chiolo I, Shubassi G, Bernstein KA, Rothstein R, Botrugno OA, Parazzoli D, Oldani A, Minucci S, et al. 2011. HDACs link the DNA damage response, processing of doublestrand breaks and autophagy. Nature 471: 74-79.

Ross AJ, Li M, Yu B, Gao MX, Derry WB. 2011. The EEL-1 ubiquitin ligase promotes DNA damage-induced germ cell apoptosis in C. elegans. Cell Death Differ 18: 1140-1149.

Shankar S, Srivastava RK. 2008. Histone deacetylase inhibitors: mechanisms and clinical significance in cancer: HDAC inhibitor-induced apoptosis. Adv Exp Med Biol 615: 261-298.
Shieh SY, Ikeda M, Taya Y, Prives C. 1997. DNA damageinduced phosphorylation of p53 alleviates inhibition by MDM2. Cell 91: 325-334.

Sieburth D, Ch'ng Q, Dybbs M, Tavazoie M, Kennedy S, Wang D, Dupuy D, Rual JF, Hill DE, Vidal M, et al. 2005. Systematic analysis of genes required for synapse structure and function. Nature 436: 510-517.

Strahl BD, Allis CD. 2000. The language of covalent histone modifications. Nature 403: 41-45.

Sun JM, Chen HY, Moniwa M, Litchfield DW, Seto E, Davie JR. 2002. The transcriptional repressor Sp3 is associated with CK2-phosphorylated histone deacetylase 2. J Biol Chem 277: 35783-35786.

Sun Q, Fan W, Chen K, Ding X, Chen S, Zhong Q. 2008. Identification of Barkor as a mammalian autophagy-specific factor for Beclin 1 and class III phosphatidylinositol 3-kinase. Proc Natl Acad Sci 105: 19211-19216.

Sun Q, Westphal W, Wong KN, Tan I, Zhong Q. 2010a. Rubicon controls endosome maturation as a Rab7 effector. Proc Natl Acad Sci 107: 19338-19343.

Sun Q, Zhang J, Fan W, Wong KN, Ding X, Chen S, Zhong Q. 2010b. The RUN domain of rubicon is important for hVps34 binding, lipid kinase inhibition, and autophagy suppression. I Biol Chem 286: 185-191.

Tan J, Cang S, Ma Y, Petrillo RL, Liu D. 2010. Novel histone deacetylase inhibitors in clinical trials as anti-cancer agents. J Hematol Oncol 3: 5. doi: 10.1186/1756-8722-3-5.

Vassilev LT, Vu BT, Graves B, Carvajal D, Podlaski F, Filipovic Z, Kong N, Kammlott U, Lukacs C, Klein C, et al. 2004. In vivo activation of the $\mathrm{p} 53$ pathway by small-molecule antagonists of MDM2. Science 303: 844-848.

Vaziri H, Dessain SK, Ng Eaton E, Imai SI, Frye RA, Pandita TK, Guarente L, Weinberg RA. 2001. hSIR2(SIRT1) functions as an NAD-dependent p53 deacetylase. Cell 107: 149-159.

Vigushin DM, Coombes RC. 2002. Histone deacetylase inhibitors in cancer treatment. Anticancer Drugs 13: 1-13.

Vogelstein B, Lane D, Levine AJ. 2000. Surfing the p53 network. Nature 408: 307-310.

Witt O, Deubzer HE, Lodrini M, Milde T, Oehme I. 2009. Targeting histone deacetylases in neuroblastoma. Curr Pharm Des 15: 436-447.

Yang Y, Do H, Tian X, Zhang C, Liu X, Dada LA, Sznajder JI, Liu J. 2010. E3 ubiquitin ligase Mule ubiquitinates Mizl and is required for TNF $\alpha$-induced JNK activation. Proc Natl Acad Sci 107: 13444-13449.

Zhao Y, Lu S, Wu L, Chai G, Wang H, Chen Y, Sun J, Yu Y, Zhou W, Zheng Q, et al. 2006. Acetylation of p53 at lysine 373/382 by the histone deacetylase inhibitor depsipeptide induces expression of p21(Waf1/Cip1). Mol Cell Biol 26: 2782-2790.

Zhao X, Heng II, Guardavaccaro D, Jiang R, Pagano M, Guillemot F, Iavarone A, Lasorella A. 2008. The HECT-domain ubiquitin ligase Huwel controls neural differentiation and proliferation by destabilizing the N-Myc oncoprotein. Nat Cell Biol 10: 643-653.

Zhong Q, Gao W, Du F, Wang X. 2005. Mule/ARF-BP1, a BH3only E3 ubiquitin ligase, catalyzes the polyubiquitination of Mcl-1 and regulates apoptosis. Cell 121: 1085-1095. 


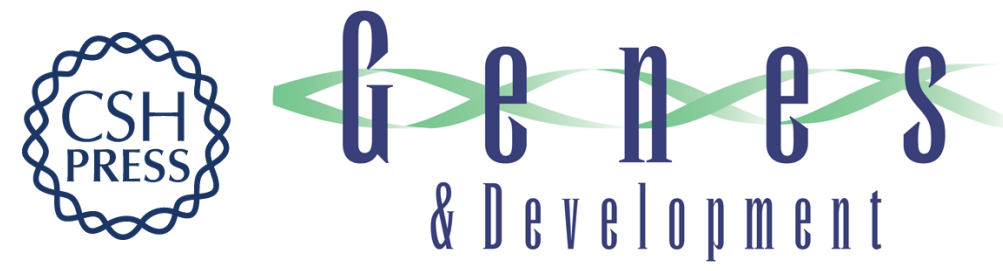

\section{Mule determines the apoptotic response to HDAC inhibitors by targeted ubiquitination and destruction of HDAC2}

Jing Zhang, Shu Kan, Brian Huang, et al.

Genes Dev. 2011, 25: originally published online October 20, 2011

Access the most recent version at doi:10.1101/gad.170605.111

\section{Supplemental http://genesdev.cshlp.org/content/suppl/2011/10/18/gad.170605.111.DC1 Material}

References This article cites 59 articles, 15 of which can be accessed free at: http://genesdev.cshlp.org/content/25/24/2610.full.html\#ref-list-1

\section{License}

Email Alerting

Receive free email alerts when new articles cite this article - sign up in the box at the top Service

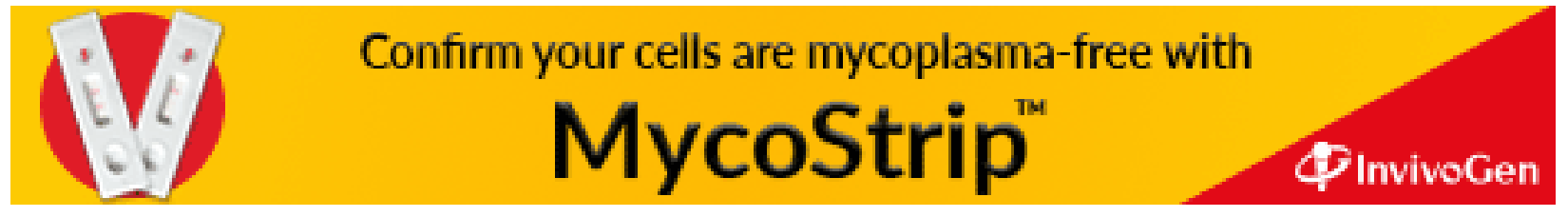

